\title{
Strong Ferritic-Steel Welds
}

\author{
H. K. D. H. Bhadeshia \\ University of Cambridge \\ Materials Science and Metallurgy \\ Pembroke Street, Cambridge CB2 3QZ, U.K. \\ www.msm.cam.ac.uk/phase-trans
}

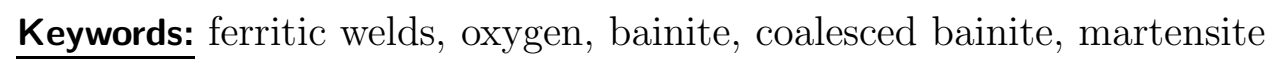

\begin{abstract}
There are many steels which are stronger than $2000 \mathrm{MPa}$, with toughness values exceeding $100 \mathrm{MPa} \mathrm{m}^{1 / 2}$ and which have been in commercial service for many decades. Examples include the marageing alloys and carbide-free bainitic steels. By contrast, welding consumables with a proof strength in excess of $1000 \mathrm{MPa}$ are few and far between. This is because whereas wrought steels can be thermomechanically processed to optimise their performance, most weld metals have to used in the as-cast condition and with impurity concentrations which are greater than is desirable. The weld metal can readily be made strong but without an accompanying ability to absorb energy during fracture, it cannot be used in practice.

A variety of experimental and theoretical approaches towards stronger weld metals are assessed here. The modern trend has been towards low-carbon mixed microstructures of bainite and martensite. This is because none of the other phases such as allotriomorphic ferrite and Widmanstätten ferrite are capable of the required strength. Conventional wisdom that the toughness of martensite can be enhanced by increasing the nickel concentration has in general proved to be unreliable. Nickel is effective only when the manganese concentration is kept to a minimum. The mechanism of the synergy between manganese and nickel is discussed in the light of recent high-resolution experiments conducted at Chalmers University and ESAB in Sweden.
\end{abstract}

\section{Introduction}

The concentration of solutes added to ferritic weld metals must be minimised in order to ensure toughness so that the welded structure can resist both residual and imposed stresses without the risk of brittle fracture. Weld metal yield strengths therefore usually lie in the range 350$550 \mathrm{MPa}$, with occasional higher values achieved at the expense of toughness, Fig. 1.

The microstructure of such weld metals consists of mixtures of allotriomorphic ferrite $(\alpha)$, Widmanstätten ferrite $\left(\alpha_{w}\right)$, acicular ferrite $\left(\alpha_{a}\right)$ and the so-called microphases (small quantities of retained austenite and martensite) [1]. Allotriomorphic ferrite is weak, and Widmanstätten ferrite suffers from poor toughness. This leaves acicular ferrite as a good strengthener which also has the ability to frequently deflect cracks; its fraction in the microstructure should therefore be as large as possible.

The total strength of a single-pass weld consists of contributions from the intrinsic strength of pure iron, solid solution strengthening and microstructural contributions from the variety of phases. This last component is only $27 \mathrm{MPa}$ when the fraction of allotriomorphic ferrite is 


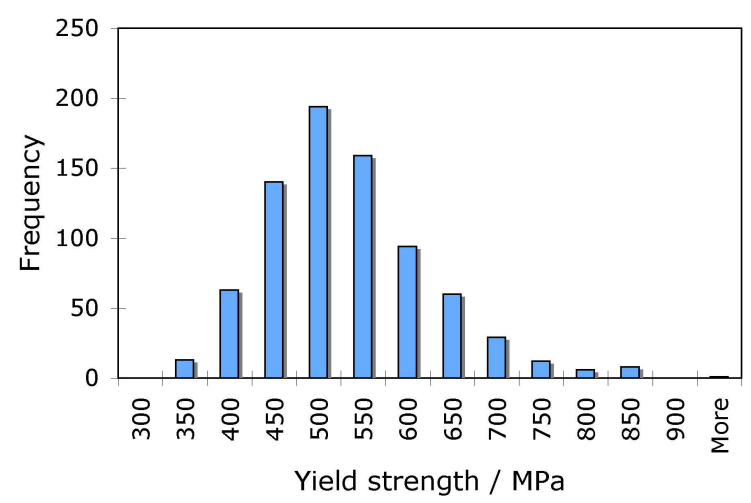

(a)

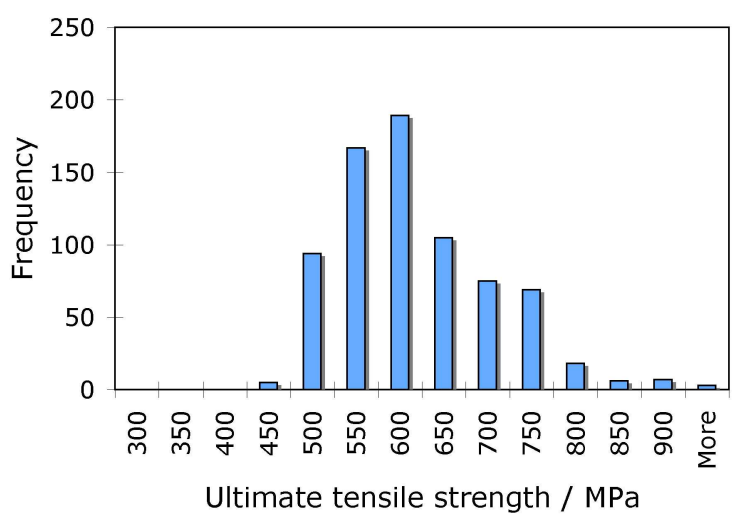

Fig. 1: Distribution of strength in ferritic steel weld metals. (a) Yield strength, 779 welds. (b) Ultimate tensile strength, 734 welds. Data from [2].

$V_{\alpha}=1,486 \mathrm{MPa}$ when $V_{\alpha_{w}}=1$ and $406 \mathrm{MPa}$ when $V_{\alpha_{a}}=1$. Since the intrinsic strength of pure iron is about $220 \mathrm{MPa}$ at ambient temperature, and since the ability to solid solution strengthen is limited by hardenability considerations, it is not surprising that the vast majority of welds based on these microstructures have strength in the range quoted above. Fig. 1 shows that there are few alloys which exceed a yield strength of $800 \mathrm{MPa}$. The term "high-strength" is therefore reserved for welds whose yield strength exceeds $800 \mathrm{MPa}$.

\section{Deviations from Conventional Microstructures}

To achieve even greater strength, it is necessary to suppress transformations to lower temperatures. This induces greater nucleation rates and leads to a refinement of microstructure. It also becomes possible to obtain phases such as lower bainite and martensite. Martensite is traditionally avoided because of its association with poor toughness in welds, but it should be recognised that not all martensite is brittle even in the untempered form. Instead, we shall see that embrittlement is more to do with poor alloy design so martensite need not be avoided in an effort to make stronger weld metals. Consider the classic case of welding alloys used in the manufacture of submarines which have high-strength tempered martensitic hulls. These typically have the composition designated "H1" in Table 1, with a microstructure that is a mixture of bainite and martensite $[3,4]$. The carbon concentration is kept low, at a value not much greater than the maximum solubility in ferrite. Although the concentration exceeds the solubility, it is well known that excess carbon is trapped at defects in the bainite and martensite, to such an extent that the effective solubility is almost the same as the total concentration [5]. It is possible in these circumstances, to completely avoid cementite precipitation [6]. To summarise, low-carbon martensite need not be brittle - indeed, commercial welding alloys based on H1 composition are strong and tough (Table 1, Fig. 2).

Unsuccessful attempts have been made $[7,8]$ to go beyond $\mathrm{H} 1$, by increasing the nickel concentration. Fig. 2 illustrates the problem, that apparent increases in toughness (for example weld H5) were really associated with dramatic reductions in strength.

The work described above $[7,8]$ was based partly on the prevailing opinion that the addition of nickel to ferrite leads to an improvement in the toughness. The mechanism for this is not clear but it is possible that nickel improves the ability of dislocations in ferrite to glide more easily, thereby making ductile failure more likely than cleavage. The cores of dislocations in ferrite can 
Table 1: Approximate compositions of a series of weld metals. Details in [7].

\begin{tabular}{|cccccccc|}
\hline & $\mathrm{H} 1$ & $\mathrm{H} 2$ & $\mathrm{H} 3$ & $\mathrm{H} 4$ & $\mathrm{H} 5$ & $\mathrm{H} 6$ & $\mathrm{H} 7$ \\
$\mathrm{C}$ wt\% & 0.05 & 0.0 .2 & 0.05 & 0.02 & 0.02 & 0.02 & 0.10 \\
$\mathrm{Mn}$ & 2.0 & 2.0 & 1.0 & 1.0 & 1.0 & 1.0 & 2.0 \\
$\mathrm{Si}$ & 0.30 & 0.30 & 0.30 & 0.30 & 0.30 & 0.30 & 1.75 \\
$\mathrm{Cr}$ & 0.45 & 0.45 & 0.45 & 0.45 & 0.00 & 0.00 & 0.00 \\
$\mathrm{Ni}$ & 3.0 & 3.0 & 4.0 & 4.0 & 4.0 & 4.0 & 2.0 \\
$\mathrm{Mo}$ & 0.6 & 0.6 & 0.6 & 0.6 & 0.6 & 0.6 & 0.2 \\
$\mathrm{Cu}$ & & & & & & 2.0 & \\
\hline
\end{tabular}
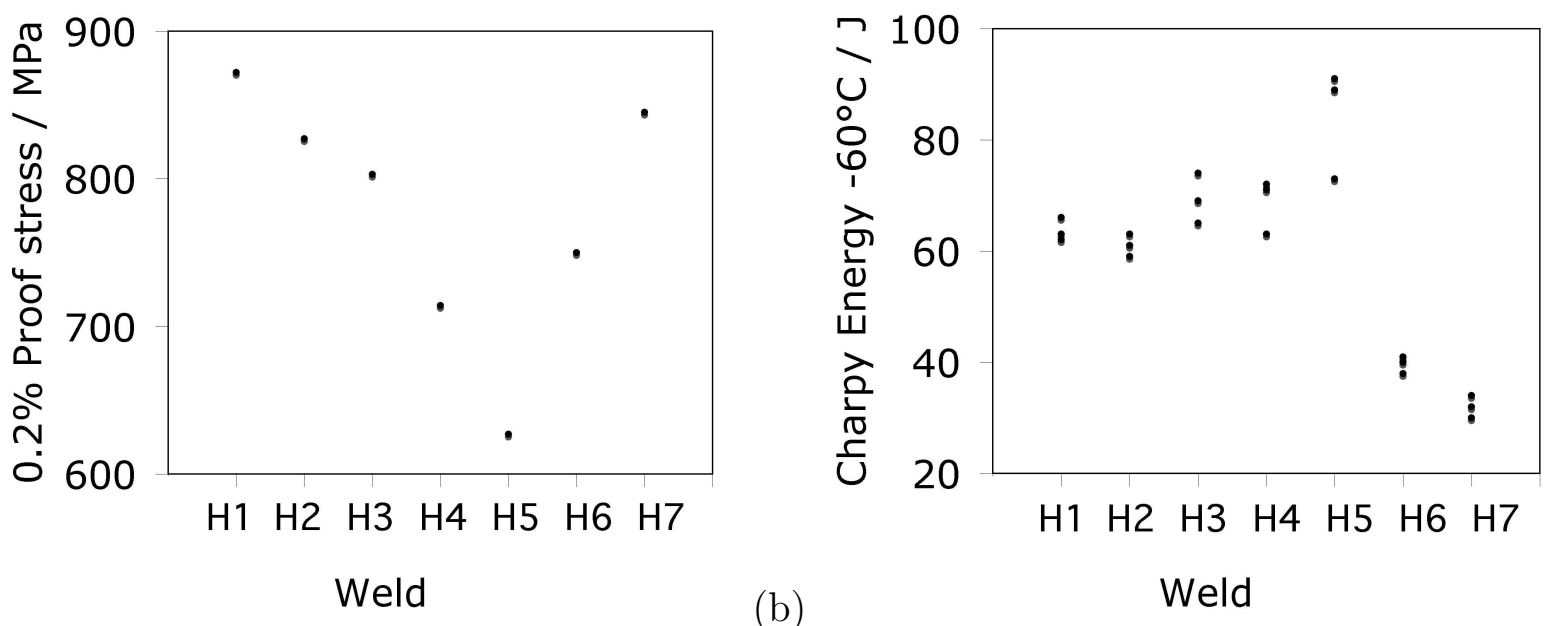

Fig. 2: The strength and toughness of the welds listed in Table 1. Data from [7].

be imagined to be three-dimensionally dissociated and nickel causes them to constrict, leading to reduction in flow stress [9].

Whereas the beneficial effect of nickel may have been verified in specific alloy systems such as steels used for cryogenic applications, it is clear from Fig. 1 that it does not always lead to better toughness in high-strength weld metals [7]. We have seen that relative to a wellestablished strong, commercial manual metal arc welding electrode (H1, Table 1), an increase in the nickel concentration actually leads to a deterioration in the Charpy energy, Fig. 1.

Murugananth and co-workers $[10,11]$ compiled a neural network model which led to the discovery that in strong weld metals, nickel is only effective in increasing toughness when the manganese concentration is small. This is illustrated in Fig. 3, where the contour plot shows the impact energy at $-60^{\circ} \mathrm{C}$ for welds $\mathrm{A}(7 \mathrm{Ni}-2 \mathrm{Mn}), \mathrm{B}(9 \mathrm{Ni} 2 \mathrm{Mn})$ and $\mathrm{C}(7 \mathrm{Ni}-0.5 \mathrm{Mn})$; the details are described elsewhere $[10,11,12]$. Experiments validated the neural network predictions so fundamental works was commenced to understand the mechanism of the $\mathrm{Ni}-\mathrm{Mn}$ phenomenon.

\section{Coalesced Bainite}

The mechanism by which a combination of high manganese and nickel concentrations leads to a deterioration in strength has been studied in detail by Keehan and co-workers $[13,14,15]$. It appears that when the transformation temperatures are sufficiently suppressed, such that there 
(a)
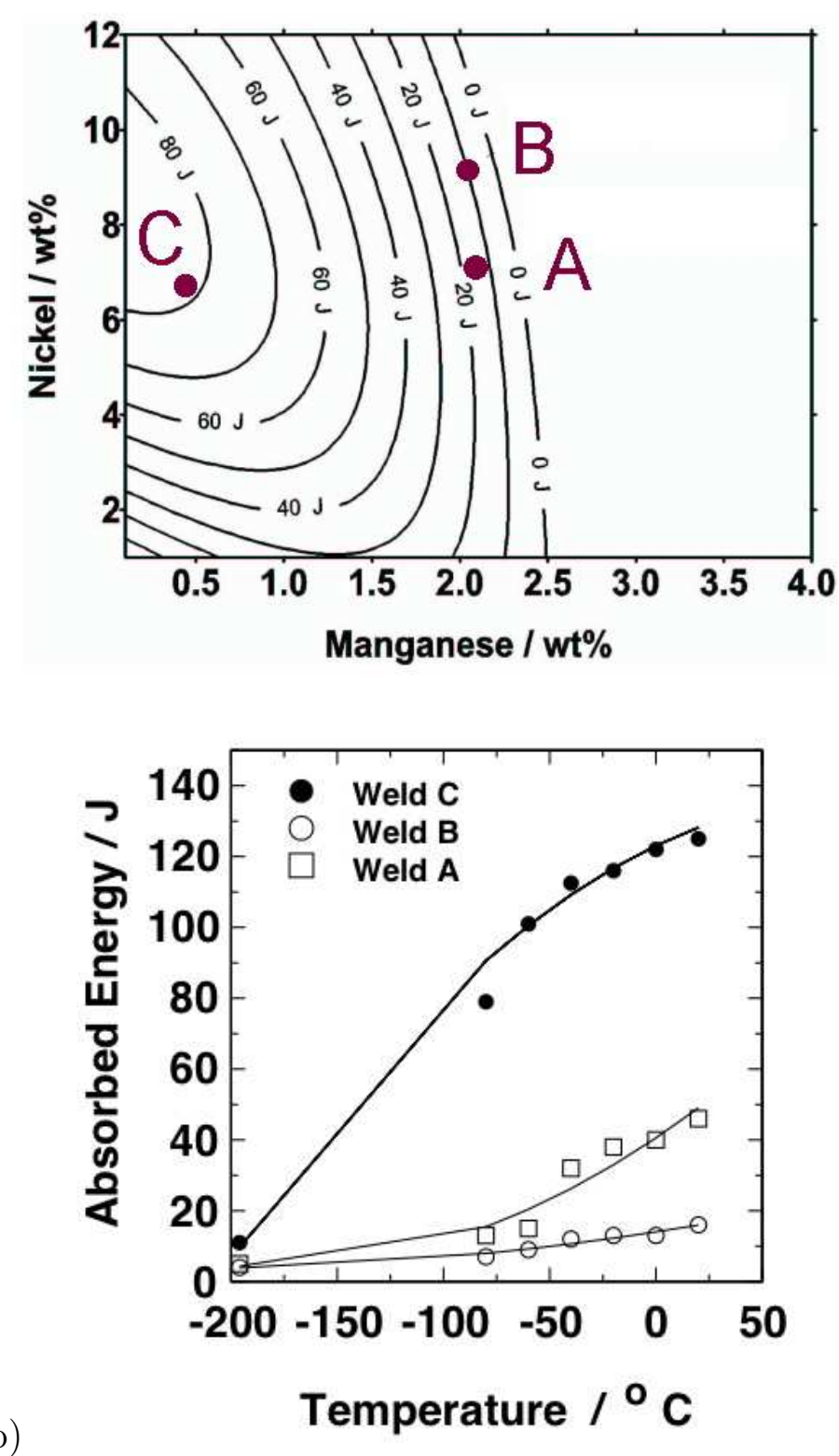

Fig. 3: (a) Contours showing the combined effect of manganese and nickel on the calculated toughness for $-60^{\circ} \mathrm{C}$, of weld metal produced using arc welding with a heat input of $1 \mathrm{~kJ} \mathrm{~mm}^{-1}$, with a base composition (wt\%) $0.034 \mathrm{C}, 0.25 \mathrm{Si}, 0.008 \mathrm{~S}, 0.01 \mathrm{P}, 0.5 \mathrm{Cr}, 0.62 \mathrm{Mo}, 0.011 \mathrm{~V}$, $0.04 \mathrm{Cu}, 0.038 \mathrm{O}, 0.008 \mathrm{Ti}, 0.025 \mathrm{~N}$, and an interpass temperature of $250^{\circ} \mathrm{C}$. (b) Full results for welds A, B, and C. 
is only a narrow gap between the bainite and martensite-start temperatures, a coarse phase labelled coalesced bainite forms.

Coalesced bainite occurs when adjacent small platelets of bainite ("sub-units") merge to form a single, larger plate [16]. This striking change in form occurs at large undercoolings. Since adjacent sub-units of bainite have an identical crystallographic orientation, they may merge given sufficient driving force to sustain the greater strain energy associated with the coarser plate, and if there is nothing to stifle the lengthening of the sub-units [16]. The first condition is satisfied by the large undercooling. The second implies that coalescence is only possible at the early stages in the transformation of austenite, when growth cannot be hindered by hard impingement with other regions of bainite.

Experiments have now confirmed that the coarse, coalesced bainite appears in weld metals containing large concentrations of both manganese and nickel, such that the bainite forms at temperatures very close to the martensite-start temperature $[13,14,15]$. It leads to a deterioration in toughness and can be avoided by careful modifications of composition, for example, by reducing the manganese concentration when the nickel concentration is high.

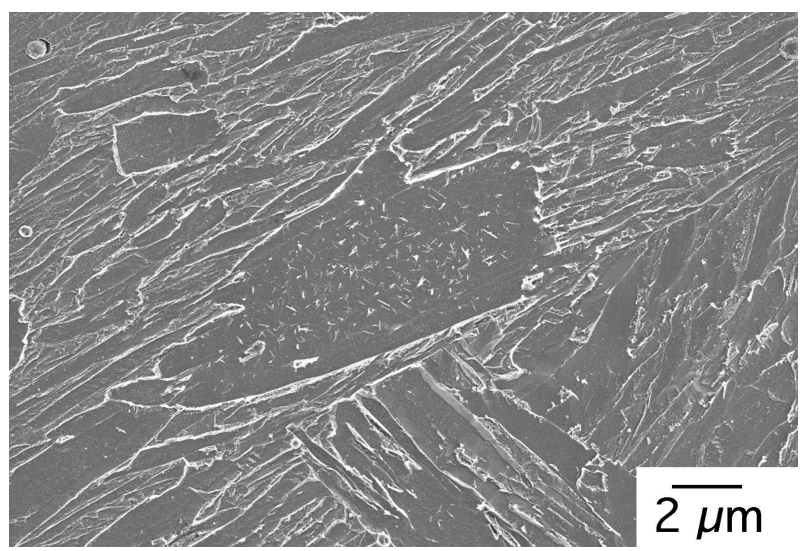

Fig. 4: Coalesced bainite in a $7 \mathrm{Ni}-2 \mathrm{Mn}$ wt\% weld metal $[13,14,15]$.

\section{Summary}

An important outcome of research on strong welds is that it is not generally true that the addition of nickel to ferritic steel weld metals leads to an increase in toughness and strength. Any increase in the nickel concentration must be balanced by a reduction in manganese in order to broaden the difference between the bainite-start and martensite-start temperatures. Otherwise, a coarse phase appears, a result of the coalescence of platelets of bainite which are in identical crystallographic orientation.

\section{References}

[1] Bhadeshia, H. K. D. H. and Svensson, L.-E., "Modelling the Evolution of Microstructure in Steel Weld Metals", Mathematical Modelling of Weld Phenomena, eds H. Cerjak and K. E. Easterling, The Institute of Materials, London, 1993, pp. 109-182.

[2] Cool, T., Bhadeshia, H. K. D. H. and MacKay, D. J. C., "The Yield and Ultimate Tensile Strength of Steel Welds", Materials Science and Engineering, 223A, pp. 186-200, 1997. 
[3] Bhadeshia, H. K. D. H. and Svensson, L.-E., "Microstructure of submerged arc--weld deposits for high-strength steels", J. Materials Science, 24, pp. 3180-3188, 1989.

[4] Bhadeshia, H. K. D. H. and Svensson, L.-E., "Design of submerged arc-weld deposits for highstrength steels", Proc. Weld Quality, The Role of Computers, Pergamon Press, Oxford, pp. 71788, July 1988.

[5] Bhadeshia, H. K. D. H. and Waugh, A. R., "Bainite: An atom probe study of the incomplete reaction phenomenon", Acta Metallurgica, 30, pp. 775-784, 1982.

[6] Kalish, D. and Cohen, M., "Structural changes and strengthening in the strain tempering of martensite", Materials Science and Engineering, 6, pp. 156-166, 1970.

[7] Lord, M., "Design and Modelling of Ultra-High Strength Steel Weld Deposits", Ph.D. Thesis, University of Cambridge, 1998.

[8] "Effect of interpass temperature on properties of high strength weld metals", Svetsaren, No. 1, pp. 53-58, 1999.

[9] Leslie, W. C., The Physical Metallurgy of Steels, McGraw-Hill, London, 1981.

[10] Murugananth, M., Bhadeshia, H. K. D. H., Keehan, E., Andrén, H.-O. and Karlsson, L., Mathematical Modelling of Weld Phenomena 6, eds H. Cerjak and H. Bhadeshia, Maney Publishers, London, pp. 205-230, 2002.

[11] Keehan E., Andrén H. O., Karlsson L., Murugananth M., Bhadeshia H. K. D. H., Microstructural and mechanical effects of nickel and manganese on high strength steel weld metals, 6th Int. Conference on Trends in Welding Research, pp. 695700, Pine Mountain, Georgia, USA, April $1519,2002$.

[12] Murugananth, M., "Design of Welding Alloys for Creep and Toughness", Ph.D. Thesis, University of Cambridge, 2002.

[13] Keehan, E., Karlsson, L. and Andrén, H.--O., "Influence of C, Mn and Ni on Strong Steel Weld Metals: Part 1, Effect of nickel", Science and Technology of Welding and Joining, 11, pp. 1-8, 2006 .

[14] Keehan, E., Karlsson, L., Andrén, H.-O. and Bhadeshia, H. K. D. H. "Influence of C, Mn and Ni on Strong Steel Weld Metals: Part 2, Increased Impact Toughness", Science and Technology of Welding and Joining, 11, pp. 9-18, 2006.

[15] Keehan, E., Karlsson, L., Andrén, H.-O. and Bhadeshia, H. K. D. H. "Influence of C, Mn and Ni on Strong Steel Weld Metals: Part 3, Increased Strength", Science and Technology of Welding and Joining, 11, pp. 19-24, 2006.

[16] Chang, L. C. and Bhadeshia, H. K. D. H., "Microstructure of lower bainite formed at large undercoolings below the bainite start temperature", Materials Science and Technology, 12, pp. 233-236, 1996.

This article was processed using the IATEX macro package with TTP style 